TITLE:

\title{
Effect of additives to supercritical methyl acetate on biodiesel production
}

AUTHOR(S):

Goembira, Fadjar; Saka, Shiro

CITATION:

Goembira, Fadjar ... [et al]. Effect of additives to supercritical methyl acetate on biodiesel production. Fuel Processing Technology 2014, 125: 114-118

ISSUE DATE:

2014-09

URL:

http://hdl.handle.net/2433/187364

RIGHT:

C 2014 Elsevier B.V.; この論文は出版社版でありません。引用の際には 出版社版をご確認ご利用ください。; This is not the published version. Please cite only the published version. 


\section{Effect of Additives to Supercritical Methyl Acetate on Biodiesel Production*}

Fadjar Goembiraa,b and Shiro Sakaa,**

aDepartment of Socio-Environmental Energy Science

Graduate School of Energy Science

Kyoto University

Yoshida-honmachi, Sakyo-ku, Kyoto 606-8501, Japan

bDepartment of Environmental Engineering

Faculty of Engineering

Andalas University

Kampus Unand Limau Manis, Padang 25163, Indonesia

${ }^{* *}$ Corresponding author

E-mail address: saka@energy.kyoto-u.ac.jp

*This work is an excerpt of PhD dissertation by F. Goembira in Kyoto University who is presently affiliated to Department of Environmental Engineering, Faculty of Engineering, Andalas University, Indonesia 


\section{Abstract}

Supercritical methyl acetate has been proven to convert triglycerides into fatty acid methyl esters (FAME) and triacetin. Due to the low reactivity of supercritical methyl acetate on triglycerides, reaction condition of $350^{\circ} \mathrm{C} / 20 \mathrm{MPa} / 45 \mathrm{~min}$ is needed to obtain the highest yield of 96.7wt\% FAME and 8.8wt\% triacetin (total 105.5wt\%). Yet, under such condition, thermal decomposition of products is inevitable, thus, further yield increments are hard to attain. This study was, therefore, done to know the possible use of additives in increasing the reaction rate of the supercritical process. Oleic acid, acetic acid, methanol and water were evaluated as the additives. It was discovered that acetic acid and water additions improved the performance of supercritical methyl acetate method. Surprisingly, when both additives were used simultaneously as aqueous acetic acid, the higher yield was obtainable at a lower reaction temperature. The addition of 10 w $1 \%$ aqueous acetic acid (25wt\% concentration) at $300^{\circ} \mathrm{C} / 20 \mathrm{MPa} / 45 \mathrm{~min}$ yielded $96.8 \mathrm{wt} \%$ FAME and $12.9 \mathrm{wt} \%$ triacetin (total $109.7 \mathrm{wt} \%$ ), thus, it is considered as a potential additive in biodiesel production by supercritical methyl acetate method.

Keywords: biodiesel, fatty acid methyl ester, triacetin, supercritical methyl acetate, aqueous acetic acid 


\section{Introduction}

The worldwide increase in biodiesel production has lead to glycerol market oversupply that reduces the value of the commodity. As a direct consequence, glycerol is no longer a value-added by-product in biodiesel production, thus, potentially increasing the cost of biodiesel production (Haas et al., 2006). The inevitable formation of glycerol from biodiesel production is caused by the extensive use of transesterification reaction, as the most popular method in biodiesel production at the moment (Ayoub and Abdullah, 2012).

Theoretically, glycerol by-production can be prevented by interesterification reaction. In comparison, transesterification reaction uses short alkyl chain alcohols such as methanol, whereas for interesterification, carboxylate esters such as methyl acetate are applied in the reaction. As a result, instead of producing glycerol as a by-product, interesterification generates triacins, such as triacetin, tripropionin or tributyrin, depending on the type of carboxylate esters used in the reaction.

Saka (2005) invented non-catalytic supercritical methyl acetate method to produce fatty acid methyl esters (FAME) and triacetin, which are both miscible at room temperature under atmospheric pressure. This mixture hardly shows any detrimental effects on biodiesel properties, thus, both can be considered as biodiesel (Saka and Isayama, 2009). Additionally, for interesterification reaction of triglycerides, supercritical 
methyl acetate gave the highest yield among various supercritical carboxylate esters (Goembira et al., 2012).

Nevertheless, due to low reactivity of triglycerides to supercritical methyl acetate, reaction condition of $350^{\circ} \mathrm{C} / 20 \mathrm{MPa} / 45 \mathrm{~min}$ at $42: 1$ molar ratio in methyl acetate to oil was needed for obtaining the high yield in biodiesel production (Goembira and Saka, 2012). Under such a reaction condition, thermal decomposition of some formed products would be possible to take place, thus, higher yields are hard to obtain from the non-catalytic supercritical process (Goembira and Saka, 2013).

This work was, therefore, carried out to find possible utilization of additives that can proceed the interesterification reaction by supercritical methyl acetate treatment under reaction conditions with the lower risks in thermal decomposition of products. Thereby, higher biodiesel yields are expected to be obtainable.

\section{Experimental}

\subsection{Materials}

Rapeseed oil (molecular weight $=883 \mathrm{~g} / \mathrm{mol}$ ) with $0.01 \mathrm{wt} \%$ free fatty acids (FFA) content and methyl acetate with purity more than 99wt\% were utilized for biodiesel production by interesterification reaction under supercritical condition. As for the additives, oleic acid, acetic acid, methanol, distilled water (purity >99wt\%) and various concentrations $(26,51$ and $76 \mathrm{w}+\%)$ of aqueous acetic acid were used in 
this study. Moreover, analytical grade of various individual FAME compounds consisted of methyl palmitate (C16:0), methyl stearate (C18:0), methyl oleate (C18:1), methyl linoleate (C18:2) and methyl linolenate (C18:3) together with triacetin were applied as standard compounds for analytical purposes. All chemicals were purchased from Nacalai Tesque Inc., Kyoto, Japan.

\subsection{Methods}

Supercritical methyl acetate treatment was carried out in a batchtype reaction system that consisted of a batch reaction vessel, a molten tin bath for supercritical treatment and water bath for quenching the reaction vessel to stop the supercritical process. The reaction vessel is equipped with a thermocouple and a pressure gauge to accurately monitor the reaction temperature and pressure, respectively. In addition, the reaction vessel has a gas charging inlet that was used to increase initial pressure by the addition of pressurized nitrogen gas in the vessel, thereby the final reaction pressure can be adjusted. Moreover, corrosive-resistant reaction vessel is made of Inconel-625 special alloy that can be used under high temperatures and pressures up to $500^{\circ} \mathrm{C}$ and 200MPa, respectively. To carry out a supercritical methyl acetate treatment under a determined reaction condition, all reagents were placed into the reaction vessel based on the molar ratio used in this study. Afterwards, without charging the unit with pressurized nitrogen, a supercritical treatment was carried out to know the final reaction 
pressure under such reaction condition. The value of final reaction pressure was then utilized for determining additional initial pressure by charging the reaction vessel by pressurized nitrogen. In that way, the reaction pressure can be adjusted in the batch-reaction system.

After removing unreacted methyl acetate and additives by vacuum evaporation instrument, obtained products were analyzed by using high performance liquid chromatography (HPLC) with a refractive index detector (RID). Cadenza CD-C18 was used as the column with methanol as the mobile phase at $1 \mathrm{~mL} / \mathrm{min}$ flow-rate. The oven temperature was set $40^{\circ} \mathrm{C}$ and $10 \mu \mathrm{L}$ of methanol-diluted sample was injected by auto-injector device into the HPLC.

Identification of products was carried out by comparing their retention times with the ones obtained from standard compounds. On the other hand, calibration curves of standard compounds were used to quantify the products based on the peak areas that are identified from HPLC chromatograms. Product yield was calculated from the weight of products divided by their theoretically obtainable weights based on the weight of triglycerides. Theoretically, in supercritical methyl acetate interesterification of triglycerides, the maximum product yield is $125 \mathrm{w}+\%$ that consists of 100 and $25 \mathrm{wt} \%$ of FAME and triacetin, respectively.

\section{Results and discussion}

\subsection{Effect of various additives on supercritical methyl acetate}


Fig. 1 shows the effect of $10 \mathrm{w}+\%$ addition of various additives on product yields from supercritical treatment of rapeseed oil at $350^{\circ} \mathrm{C} / 20 \mathrm{MPa} / 42$ molar ratio. If we define the process performance as the amount of total FAME and triacetin produced, we can clearly see that only acetic acid and water additions can give better performance to the supercritical process.

In the case of acetic acid addition, the highest yield was obtained at $45 \mathrm{~min}$ reaction time, i.e., 94.2 and 14.1 wt\% FAME and triacetin, respectively (108.3wt\% total yield). In comparison, under the same reaction condition, $96.7 \mathrm{w}+\%$ FAME and $8.8 \mathrm{w}+\%$ triacetin $1105.5 \mathrm{w}+\%$ total yield) were obtained in the absence of the additive. Campanelli et al. (2009) reported the same behavior from the addition of acetic acid in supercritical methyl acetate treatment for biodiesel production. This situation was most likely due to the acidolysis of triglycerides by acetic acid that increased the formation of triacetin and the availability of FFA in the process. This finding is in accordance with the one published by Saka et al. (2009), which demonstrates that triglycerides can be acidolyzed by acetic acid under its subcritical state to produce FFA and triacetin. Since FFA has higher reactivity than triglycerides towards supercritical methyl acetate (Saka and Isayama, 2009), higher yields were achievable.

On the other hand, the addition of $10 \mathrm{wt} \%$ water to the same reaction condition mentioned earlier resulted in significant yield increase 
under a shorter reaction time. The highest total yield of $99.4 \mathrm{wt} \%(91.1 \mathrm{wt} \%$ FAME and $8.3 w+\%$ triacetin) was obtained in $15 \mathrm{~min}$ reaction time due to the presence of water as an additive. In comparison, only $70.9 \mathrm{w}+\%$ FAME and $3.3 \mathrm{w} t \%$ triacetin (total yield of $74.2 \mathrm{w}+\%$ ) were acquired under the same condition but without the additive addition. The increase of reaction rate due to the addition of water as an additive was presumably due to the hydrolysis process of triglycerides by water to produce FFA and glycerol. As stated earlier, FFA has higher reactivity than triglycerides towards supercritical methyl acetate, thus, higher yields were possible at shorter reaction time if the triglycerides were already hydrolyzed into FFA and glycerol.

\subsection{Potential additive for supercritical methyl acetate}

In order to know the potential of water or acetic acid as an additive, experiments were repeated under the same reaction condition but with various reaction temperatures. The results of this experiment are presented in Fig. 2. We can clearly observe from the figure that at reaction temperatures of 270 and $300^{\circ} \mathrm{C}$, water addition gave higher product yields than the addition of acetic acid. This situation indicates that the hydrolysis proceeded faster than the acidolysis of triglycerides.

However, at this point, we can see that the individual addition of water or acetic acid to the supercritical methyl acetate process under reaction temperatures of 270 and $300^{\circ} \mathrm{C}$ could not give higher product yields than the one obtained at $350^{\circ} \mathrm{C}$. It is, therefore, motivating to know 
the simultaneous effect of those additives in the form of aqueous acetic acid $\left(\mathrm{CH}_{3} \mathrm{COOH}_{(\mathrm{aq})}\right)$ on the supercritical process.

Under the same reaction condition of $350^{\circ} \mathrm{C} / 20 \mathrm{MPa}, 10 \mathrm{wt} \%$ of three different concentrations of $\mathrm{CH}_{3} \mathrm{COOH}_{(\text {aq) }}$, i.e., 26, 51 and 76wt\% concentrations, was added to the supercritical methyl acetate treatment of rapeseed oil and the results are shown in Fig. 3. The highest yield of $93.1 \mathrm{wt \%}$ FAME and $9.2 \mathrm{wt \%}$ triacetin (total yield of $102.3 \mathrm{w}+\%$ ) was obtained at $15 \mathrm{~min}$ reaction time, due to the addition of $10 \mathrm{wt} \%$ $\mathrm{CH}_{3} \mathrm{COOH}_{(\text {aq) }}$ (26wt\% concentration). Longer reaction time, however, resulted in lower yields.

On the other hand, the additions of higher $\mathrm{CH}_{3} \mathrm{COOH}_{(\mathrm{aq})}$ concentrations, i.e., 51 and 76wt\%, oppositely show the needs for longer reaction time to obtain the highest yield. It can, therefore, be concluded from these findings that the 26 wt\% concentration of $\mathrm{CH}_{3} \mathrm{COOH}_{(\mathrm{aq})}$ was the most potential additive to improve the reaction rate of supercritical methyl acetate treatment in biodiesel production.

Fig. 4 shows HPLC chromatograms of products from supercritical methyl acetate treatment of rapeseed oil with 10 wt\% $\mathrm{CH}_{3} \mathrm{COOH}_{\text {(aq) }}$ (26wt\% concentration). From this figure, we can see the absence of intermediate peaks in all reaction times, which indicates that the reaction was almost complete even at the shortest reaction time. The reduction of product yields under longer reaction time in supercritical treatments was most likely due to thermal decomposition of some 
formed product, particularly the poly-unsaturated FAME, as reported by Imahara et al. (2008).

Furthermore, Fig. 5 shows the comparison of product yields from supercritical methyl acetate treatment of rapeseed oil under various reaction temperatures, with and without the addition of $\mathrm{CH}_{3} \mathrm{COOH}_{(\mathrm{aq})}$ (26wt\% concentration). We can see that the addition of the additive significantly improved the supercritical process by obtaining the highest total yield of $109.7 w t \% \quad(96.8 w t \%$ FAME and $12.9 w t \%$ triacetin) at $300^{\circ} \mathrm{C} / 20 \mathrm{MPa} / 45 \mathrm{~min}$. On the other hand, a lower reaction temperature of $270^{\circ} \mathrm{C}$ under $20 \mathrm{MPa}$ in reaction pressure could not give any satisfactory yields, even though $\mathrm{CH}_{3} \mathrm{COOH}_{(\text {aq) }}$ (26wt\% concentration) was employed as the additive.

Moreover, Fig. 6 shows the yields from supercritical methyl acetate treatment at $300^{\circ} \mathrm{C} / 20 \mathrm{MPa}$, with and without the addition of $\mathrm{CH}_{3} \mathrm{COOH}_{(\mathrm{aq})}(26 \mathrm{wt} \%$ concentration) under a prolonged reaction time up to $60 \mathrm{~min}$. The figure exhibits that reaction time more than $45 \mathrm{~min}$ resulted in yield reduction in the process, which is most likely due to thermal decomposition of poly-unsaturated FAME. In comparison, under the same reaction condition, the absence of the additive resulted in Owt\% yield.

The increase of the product yield in the addition of $\mathrm{CH}_{3} \mathrm{COOH}_{(a q)}$ (26wt\% concentration) was presumably due to the simultaneous acidolysis and hydrolysis of triglycerides that increase the formation of 
FAME and triacetin. Furthermore, the use of lower reaction temperature under high reaction pressure might contribute to lesser thermal decomposition from taking place, thus, higher product yields were achievable.

Based on these lines of evidence, it is clear that the addition of $10 \mathrm{w}+\% \mathrm{CH}_{3} \mathrm{COOH}_{(\mathrm{aq})}(26 \mathrm{w}+\%$ concentration) has improved the reaction rate of supercritical methyl acetate method in biodiesel production, by producing higher product yields at lower reaction temperatures under high reaction pressure. The biodiesel production process with the addition of $\mathrm{CH}_{3} \mathrm{COOH}_{(\text {aq) }}$ as an additive is shown in Fig. 7. In this process, oils are treated with supercritical methyl acetate in the presence of the additive. After removal of unreacted methyl acetate and the additive by a simple vacuum evaporation step, biodiesel that consists of FAME and triacetin is obtainable.

\section{Concluding remarks}

This study was done to improve the reaction rate of glycerol-free supercritical methyl acetate method in biodiesel production, by the application of additives in the process. Among various additives used in this study, acetic acid and water could improve the yields from the supercritical process by different roles. Acetic acid acidolyzed triglycerides to form triacetin and FFA, thus, higher product yields were observable due to direct formation of triacetin and higher reactivity of supercritical methyl acetate towards FFA as compared to triglycerides. 
On the other hand, water addition promoted hydrolysis of triglycerides to generate FFA and glycerol, in which the formation of FAME in the supercritical process was enhanced. Moreover, the simultaneous effect of acetic acid and water was exhibited by the application of $\mathrm{CH}_{3} \mathrm{COOH}_{(\mathrm{aq})}$ as an additive. The addition of $10 \mathrm{wt} \% \mathrm{CH}_{3} \mathrm{COOH}_{(\text {aq) }}(26 \mathrm{wt} \%$ concentration) in supercritical methyl acetate resulted in the highest total yield of $109.7 \mathrm{w}+\%$ (96.8wt\% FAME and $12.9 \mathrm{wt} \%$ triacetin) under reaction condition of $300^{\circ} \mathrm{C} / 20 \mathrm{MPa} / 45 \mathrm{~min} / 42$ molar ratio. The higher yield was not only resulted from the higher reaction rate due to the addition of the additive, but also due to the possible reduction in thermal decomposition of products under such a reaction condition.

\section{References}

Ayoub M, Abdullah AZ (2012) Critical Review on the Current Scenario and Significance of Crude Glycerol Resulting from Biodiesel Industry towards More Sustainable Renewable Energy Industry. Renewable and Sustainable Energy Reviews 16:2671-2686.

Campanelli, P, Banchero M, Manna $L$ (2010) Synthesis of Biodiesel from Edible, Non-Edible and Waste Cooking Oils via Supercritical Methyl Acetate Transesterification. Fuel 89:3675-3682.

Goembira F, Saka S (2012) Factors Affecting Biodiesel Yield in Interesterification of Rapeseed Oil by Supercritical Methyl Acetate. In: Yao T (Ed.) Zero-Carbon Energy Kyoto 2011, Green Energy and Technology:147-152. Springer.

Goembira F, Matsuura K, Saka S (2012) Biodiesel Production by Various Supercritical Carboxylate Esters. Fuel 97:373-378. 
Goembira F, Saka S (2013) Optimization of Biodiesel Production by Supercritical Methyl Acetate. Bioresource Technology 131:47-52.

Haas MJ, McAloon AJ, Yee, WC, Foglia TA (2006) A Process Model to Estimate Biodiesel Production Cost. Bioresource Technology 97:671678.

Imahara H, Minami E, Hari S, Saka S (2008) Thermal Stability of Biodiesel in Supercritical Methanol. Fuel 87:1-6.

Saka S (2005) Manufacturing Method for Fatty Acid Methyl Esters. Japan Patent no. 4378534 (application: 19 Dec 2005; granted: 2 Oct 2009).

Saka S, Isayama Y (2009) A New Process for Catalyst-Free Production of Biodiesel Using Supercritical Methyl Acetate. Fuel 88:1307-1313.

Saka S, Isayama Y, Ilham Z, Jiayu X (2009) New Process for Catalyst-Free Biodiesel Production Using Subcritical Acetic Acid and Supercritical Methanol. Fuel 89:1442-1446. 


\section{Figure Captions}

Fig. 1 Effect of $10 w+\%$ addition of various additives on supercritical methyl acetate treatment of rapeseed oil at $350^{\circ} \mathrm{C} / 20 \mathrm{MPa} / 42$ molar ratio

Fig. 2 Effect of 10 wt\% addition of a) water and b) acetic acid on supercritical methyl acetate treatment of rapeseed oil at $20 \mathrm{MPa} / 42$ molar ratio and various reaction temperatures

Fig. 3 Effect of $10 w+\%$ addition of $\mathrm{CH}_{3} \mathrm{COOH}_{(\mathrm{aq})}$ under various concentrations on supercritical methyl acetate treatment of rapeseed oil at $350^{\circ} \mathrm{C} / 20 \mathrm{MPa} / 42$ molar ratio

Fig.4 HPLC chromatograms from supercritical methyl acetate treatment of rapeseed oil at $350^{\circ} \mathrm{C} / 20 \mathrm{MPa} / 42$ molar ratio with $10 \mathrm{w}+\%$ addition of $\mathrm{CH}_{3} \mathrm{COOH}_{\text {(aq) }}(26 \mathrm{w}+\%$ conc.)

Fig.5 Effect of a) no additives and b) 10 wt\% addition of $\mathrm{CH}_{3} \mathrm{COOH}_{(\text {aq) }}$ (26wt\% conc.) on supercritical methyl acetate treatment of rapeseed oil under $20 \mathrm{MPa} / 42$ molar ratio and various reaction temperatures

Fig. 6 Yield from supercritical methyl acetate treatment of rapeseed oil at $300^{\circ} \mathrm{C} / 20 \mathrm{MPa} / 42: 1$ (mol $\left./ \mathrm{mol}\right)$ with/without $\mathrm{CH}_{3} \mathrm{COOH}_{\text {(aq) }}$ (26w+\% conc.) additions

Fig. 7 Supercritical methyl acetate method with $10 \mathrm{w}+\%$ $\mathrm{CH}_{3} \mathrm{COOH}_{\text {(aq) }}(26 \mathrm{wt} \%$ conc.) addition as an additive 

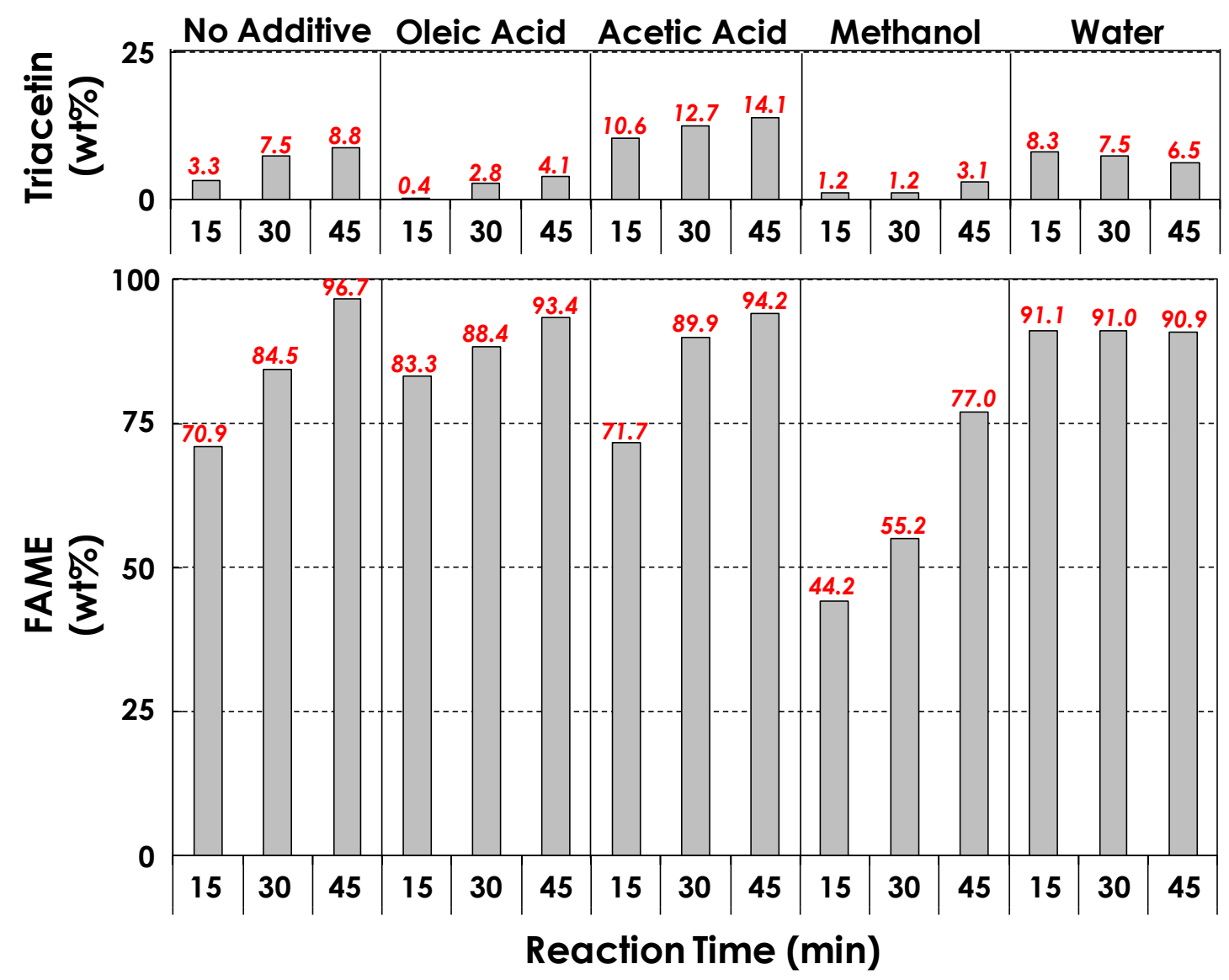

Fig. 1 Effect of 10 wt\% addition of various additives on supercritical methyl acetate treatment of rapeseed oil at $350^{\circ} \mathrm{C} / 20 \mathrm{MPa} / 42$ molar ratio 


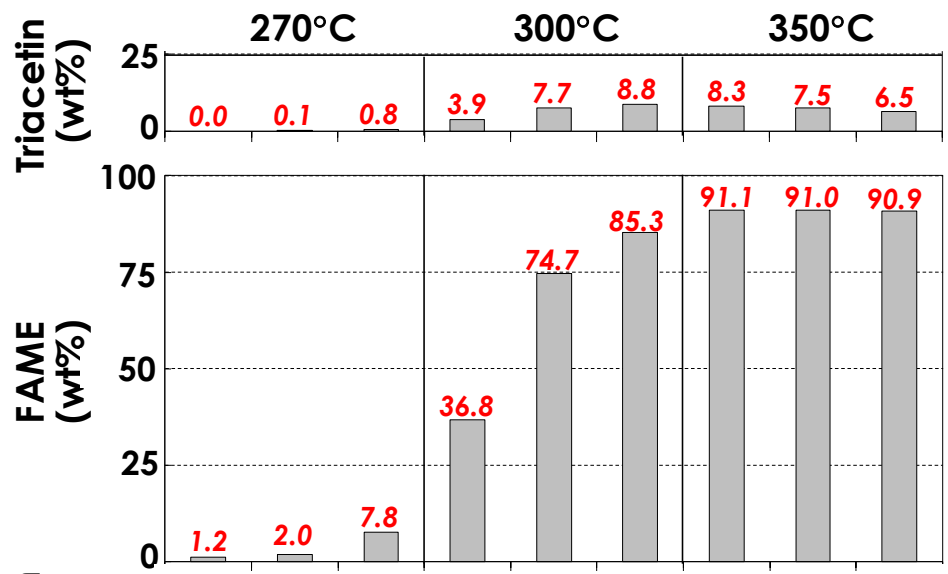

a) Water Addition

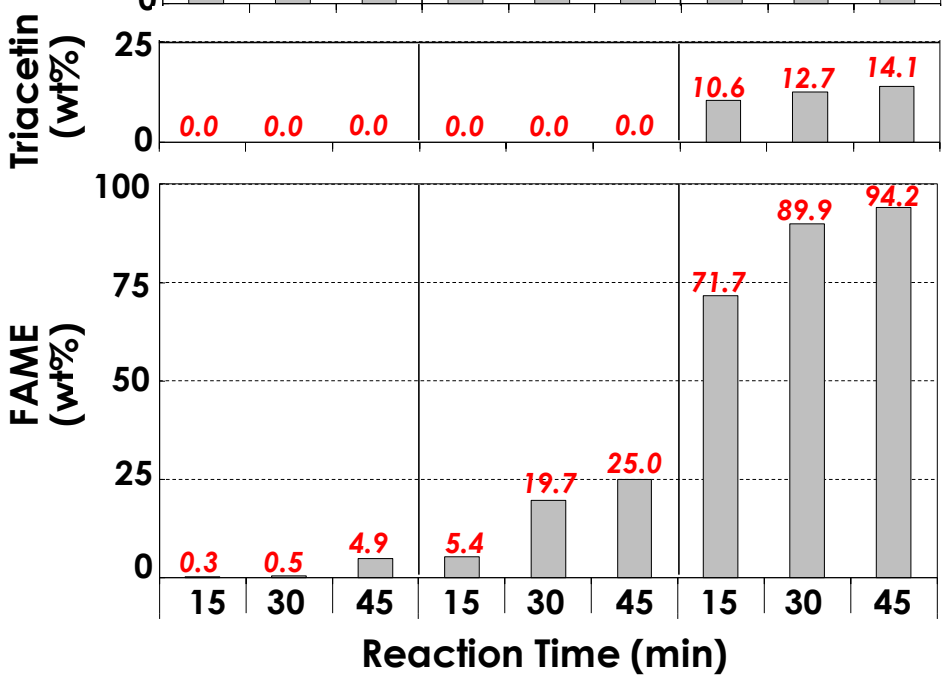

b) Acetic Acid Addition

Fig. 2 Effect of $10 w+\%$ addition of a) water and b) acetic acid on supercritical methyl acetate treatment of rapeseed oil at 20MPa/42molar ratio and various reaction temperatures 

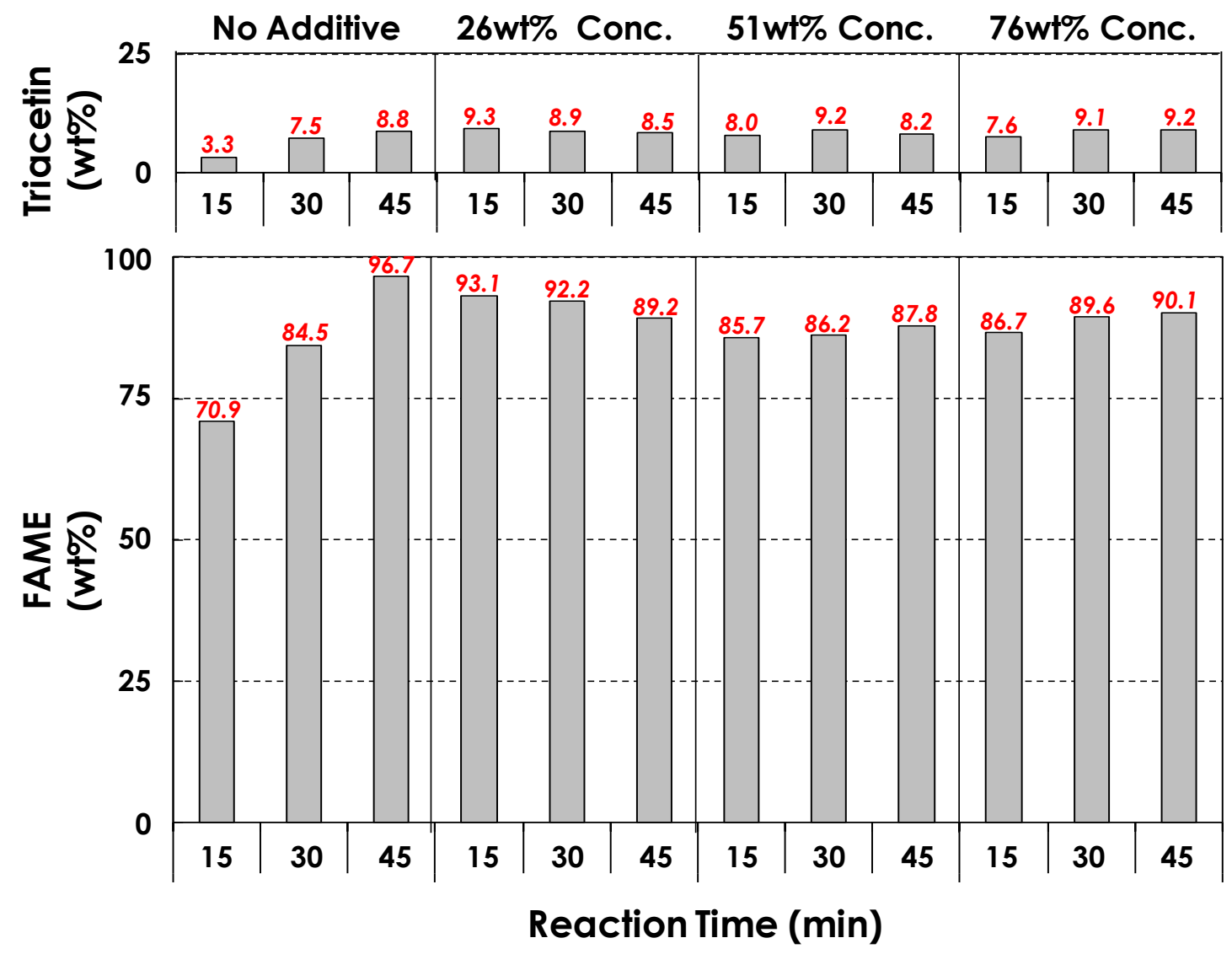

Fig. 3 Effect of 10 wt\% addition of $\mathrm{CH}_{3} \mathrm{COOH}_{\text {(aq) }}$ under various concentrations on supercritical methyl acetate treatment of rapeseed oil at $350^{\circ} \mathrm{C} /$ $20 \mathrm{MPa} / 42$ molar ratio 


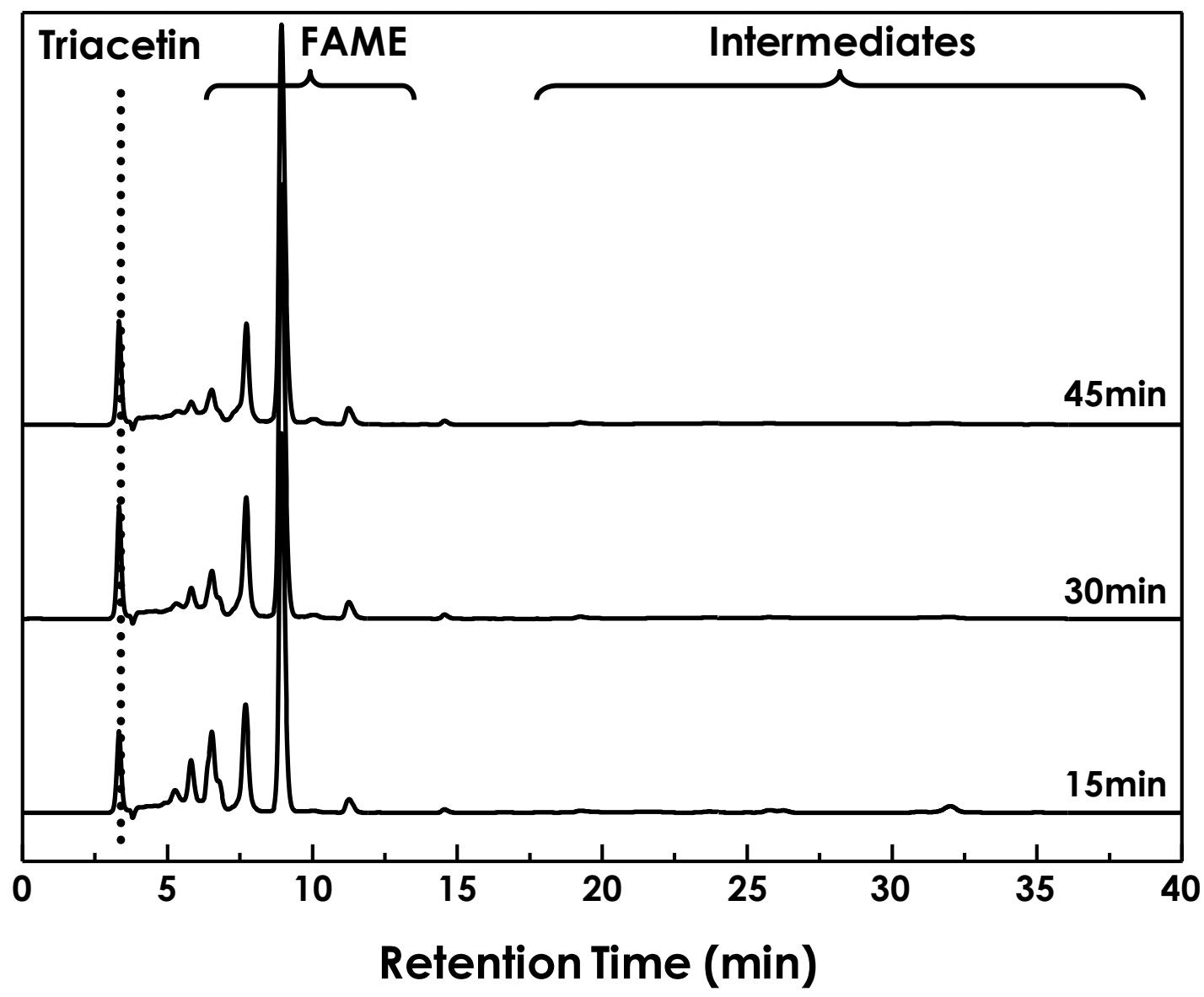

Fig. 4 HPLC chromatograms from supercritical methyl acetate treatment of rapeseed oil at $350^{\circ} \mathrm{C} /$ $20 \mathrm{MPa} / 42$ molar ratio with $10 \mathrm{wt} \%$ addition of $\mathrm{CH}_{3} \mathrm{COOH}_{(\mathrm{aq})}$ (26wt\% conc.) 


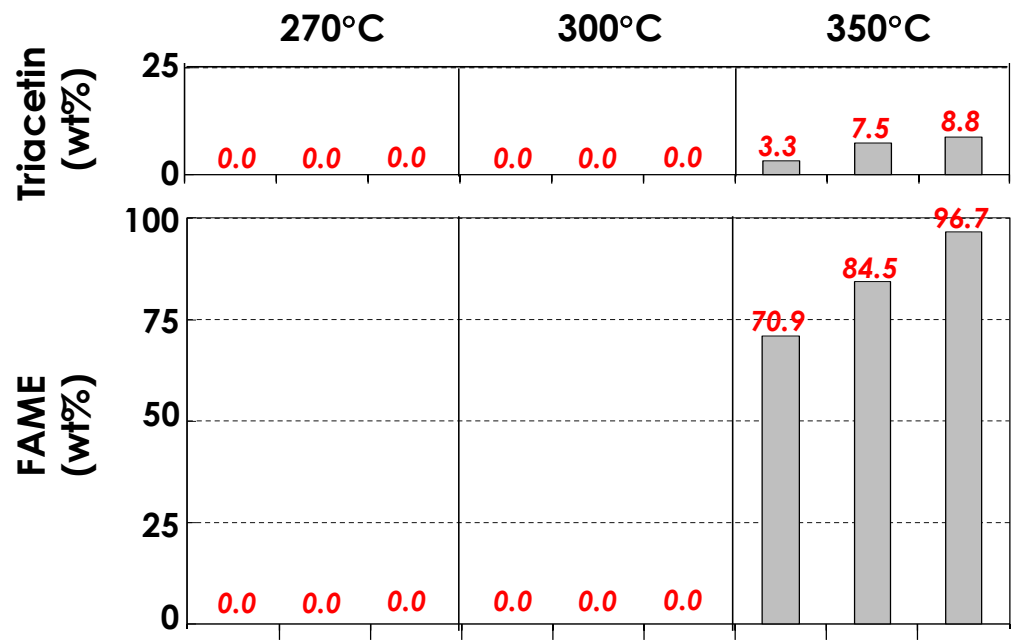

重
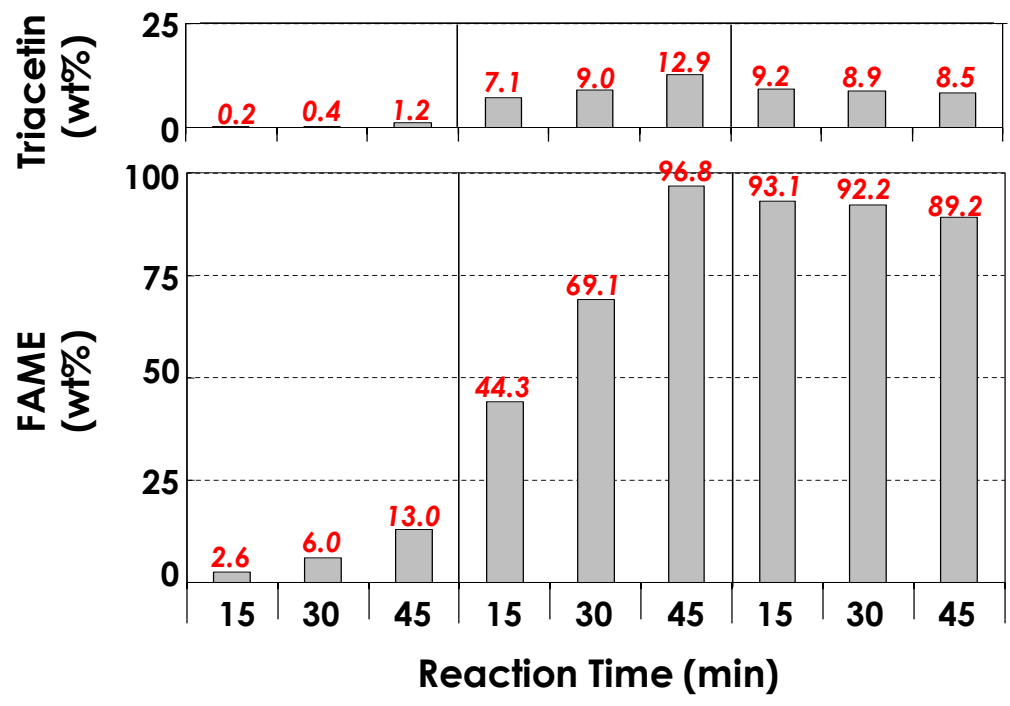

b) Addition of $10 \mathrm{wt} \% \mathrm{CH}_{3} \mathrm{COOH}_{\text {(aq) }}$ (26wt\% Conc.)

Fig.5 Effect of a) no additives and b) $10 \mathrm{wt} \%$ addition of $\mathrm{CH}_{3} \mathrm{COOH}_{\text {(aq) }}$ (26wt\% conc.) on supercritical methyl acetate treatment of rapeseed oil under 20MPa/42 molar ratio and various reaction temperatures 


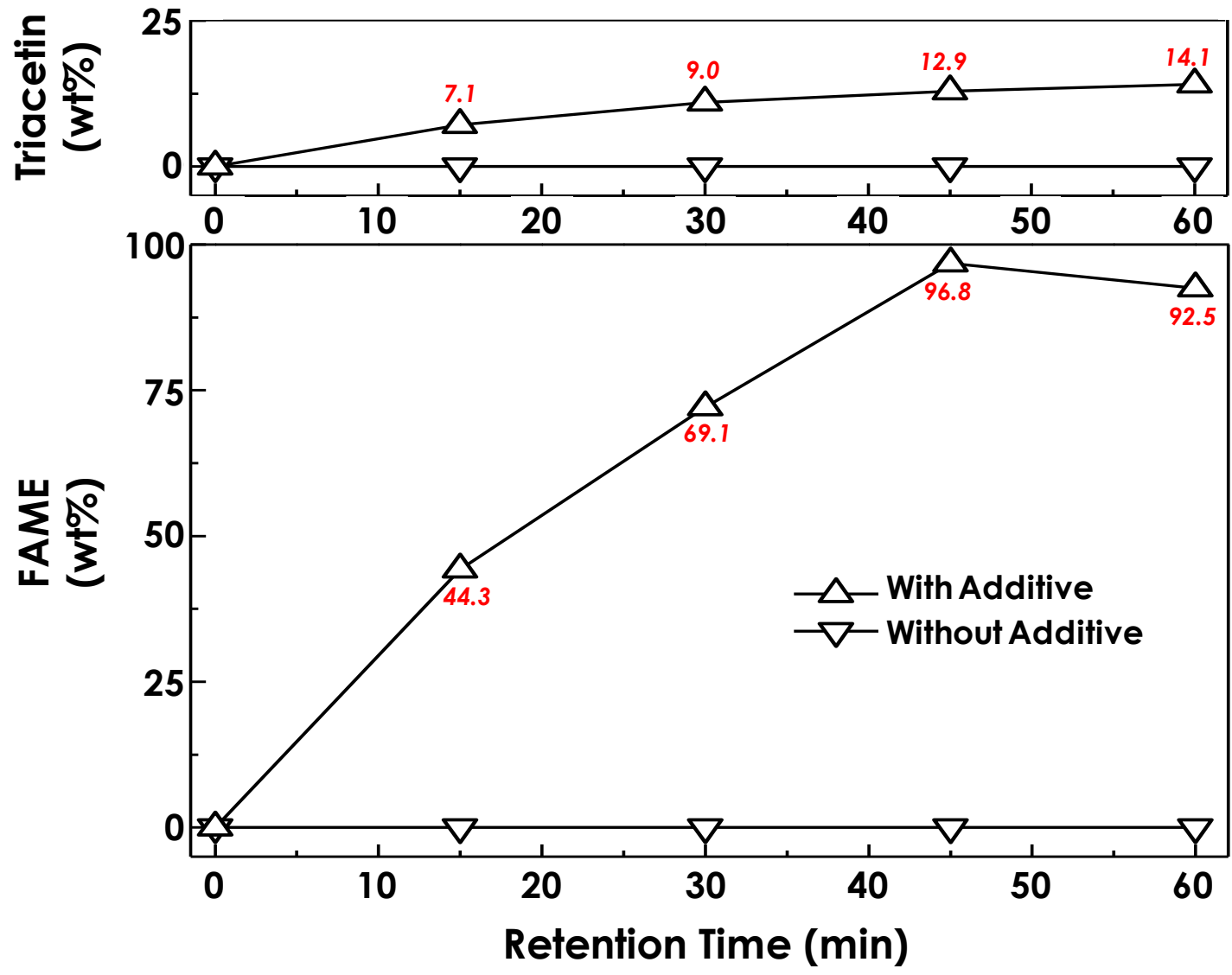

Fig. 6 Yield from supercritical methyl acetate treatment of rapeseed oil at $300^{\circ} \mathrm{C} / 20 \mathrm{MPa} / 42: 1$ (mol $\left./ \mathrm{mol}\right)$ with/without $\mathrm{CH}_{3} \mathrm{COOH}_{(\mathrm{aq})}$ (26w $+\%$ conc.) additions 


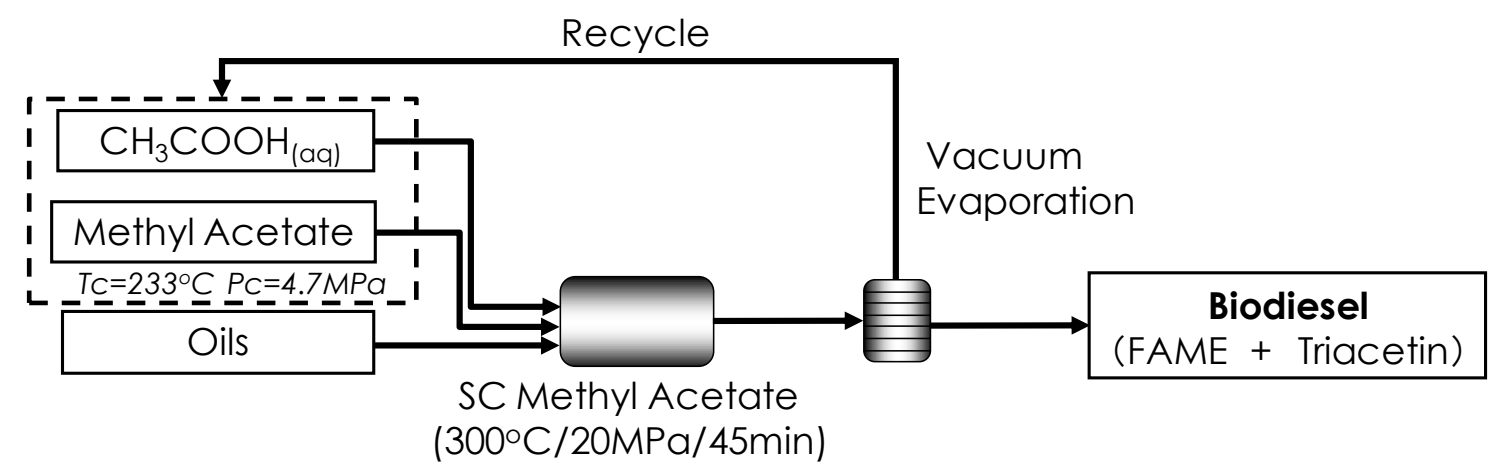

Fig. 7 Supercritical methyl acetate method with 10wt\% $\mathrm{CH}_{3} \mathrm{COOH}_{\text {(aq) }}$ (26wt\% conc.) addition as an additive 